\title{
Dampak Implementasi Green Weeding Terhadap Pemanfaatan Koleksi Usang (Studi Kasus di Perpustakaan Universitas Islam Indonesia Yogyakarta)
}

\author{
Ramadhani Ginting \\ Konsentrasi IImu Perpustakaan dan Informasi, Pascasarjana UIN Sunan Kalijaga Yogyakarta \\ email: rd950130@gmail.com
}

\begin{abstract}
In the process of developing collections in the library, there are several stages of activities carried out, one of which is weeding. This activity is very important in updating library collections and selecting library materials that are served based on conformity with user needs (user oriented) because basically, weeding activities play an important role in sorting library materials that are no longer feasible, both physically and content. However, there are several factors that cause librarians to feel that weeding activities do not need to be done or there is a sense or reluctance to do so. This is what can be an obstacle in maximizing the role of the library as a means of providing up to date and relevant information.

This study uses a qualitative descriptive method, with interview instruments. Case studies were appointed from the library of Indonesian Islamic University (UII) Yogyakarta which did not implement green weeding activities. This research was conducted to be able to describe or describe the impact of implementing green weeding on the use of absolete or useless collections at the college library. Thus, the significant impact can create a new paradigm for librarians to pay more attention to the essence of these activities and start making discourses, then apply the policy periodically.
\end{abstract}

\begin{abstract}
Abstrak
Dalam proses pengembangan koleksi di perpustakaan, terdapat beberapa tahapan kegiatan yang dilakukan, salah satunya adalah penyiangan (weeding). Kegiatan ini sangat penting dalam memutakhirkan koleksi perpustakaan dan menyeleksi bahan pustaka yang dilayankan berdasarkan kesesuaian dengan kebutuhan penggunanya (user oriented). Pada dasarnya, kegiatan weeding berperan penting dalam memilah bahan pustaka yang sudah tidak layak lagi, baik secara fisik maupun isi. Namun, terdapat beberapa faktor yang menyebabkan pustakawan merasa bahwa kegiatan weeding tidak perlu dilakukan atau ada rasa keengganan untuk melakukannya. Hal tersebutlah yang dapat menjadi penghambat dalam memaksimalkan peran perpustakaan sebagai sarana penyedia informasi yang up to date dan relevan.

Penelitian ini menggunakan metode deskriptif kualitatif, dengan instrumen wawancara. Studi kasus diangkat dari Perpustakaan Islam Indonesia (UII) Yogyakarta yang tidak menerapkan kegiatan green weeding. Riset ini dilakukan untuk dapat mendeskripsikan dampak dari pengimplementasian green weeding terhadap pemanfaatan koleksi usang (useless) pada perpustakaan perguruan tinggi. Dampak yang signifakan tersebut dapat membuat paradigma baru bagi pustakawan untuk lebih memperhatikan esensi kegiatan tersebut dan mulai membuat wacana, lalu menerapkan kebijakan tersebut secara berkala
\end{abstract}

\section{A. PENDAHULUAN}

Saat ini telah terjadi pelimpahan informasi (informationoverload) yang merupakan konsekuensi adanya perkembangan ilmu pengetahuan dan teknologi. Hal tersebut ditandai dengan banyaknya karya-karya yang telah diterbitkan, baik berbentuk tercetak maupun elektronik. Dengan semakin bertambahnya jumlah karya tersebut, maka

\author{
Keywords: \\ Weeding \\ Green Weeding \\ College Library
}

\author{
Kata Kunci: \\ Efektivitas \\ kemas ulang informasi \\ literasi informasi \\ video tutorial \\ e-resources \\ Perpustakaan Univeritas \\ Gadjah Mada
}

pengelola perpustakaan yang bertugas mengelola informasi dan pengetahuan di perpustakaan harus mampu dalam memproses sumber-sumber informasi tersebut agar koleksi yang dikelola itu hendaknya sesuai kebutuhan pemustaka dan juga tetap mengikuti perkembangan zaman.

Apabila penambahan jumlah koleksi perpustakaan secara dinamis, dan tidak diikuti 
perkembangan infrastruktur perpustakaan, maka akan bersifat statis. Tidak adanya keseimbangan tersebut menyebabkan rak-rak buku penuh dan memberi kesan yang berantakan. Degan demikian, pemustaka kesulitan menemukan koleksi yang diinginkannya. Selain itu, dengan cepat dan pesatnya tingkat pertumbuhan koleksi di perpustakaan, maka perlu dilakukan tindakan penyiangan (weeding). Alasan tersebut didasari karena adanya keterbatasan tempat tampung koleksi yang dimiliki suatu perpustakaan, itu juga untuk mengkondisikan bahan pustaka yang sudah tidak dibutuhkan lagi (Rusmana, 2001).

Sebenarnyaperpustakaandapatmeningkatkan layanan kepada pemustaka dengan optimalisasi pemanfaatan koleksi dan mengimplementasikan green weeding di Perpustakaan. Ada beberapa aspek yang menjadi poin penting dalam green weeding, misalnya dengan menjalin kerja sama dengan rumah baca. Untuk itu, dibutuhkan konsistensi dalam pembentukan kebijakan tentang penyiangan koleksi dan green weeding di perpustakaan secara jelas.

Untuk itu, dalam tulisan ini akan dijelaskan tentang bagaimana dampak implementasi green weeding terhadap pemanfaatan koleksi usang (useless) pada perpustakaan perguruan tinggi.

\section{B. KAJIAN TEORI}

\section{Weeding di Perpustakaan}

Menurut Evans dalam Urwanto (2017) menyatakan penyiangan (weeding) adalah kegiatan di perpustakaan yang memindahkan atau menarik koleksi yang berlebihan salinannya dan jarang digunakan. selain itu juga memiliki arti menghapuskan koleksi dari area koleksi utama. Sedangkan menurut (Reitz, 2004), weeding adalah suatu proses kegiatan untuk memeriksa setiap item dalam koleksi perpustakaan berdasarkan judul perjudul untuk mengidentifikasi koleksi yang akan ditarik secara permanen, namun telah memenuhi kriteria penyiangan yang sudah ditetapkan sebelumnya, khususnya ketika ruang penyimpan telah terbatas.

Berdasarkan pernyataan di atas, dapat dimaknai bahwa weeding merupakan salah satu dari berbagai kegiatan perpustakaan yang menyeleksi dan menarik bahan pustaka dari area koleksi utama berdasarkan kriteria yang telah ditentukan. Kegiatan ini untuk memberikan ruang (space) baru bagi koleksi yang diadakan kembali sesuai kebutuhan pemustaka.

Beberapa tujuan dari pelaksanaan kegiatan weeding menurut Rusmana (2001), yaitu:

1. Membina dan memperbaiki nilai pelayanan informasi oleh perpustakaan. kegiatan weeding bertujuan memutakhirkan informasi dari koleksi yang ada.

2. Memperbaiki penampilan atau kinerja suatu perpustakaan, yaitu dengan tertatanya rak-rak dengan rapi dan pustakawan dapan melakukan shelving tanpa hambatan.

3. Meningkatkan daya guna dan hasil guna ruang dari koleksi, yaitu membuat space baru.

Menurut Rusmana (2001) juga terdapat pedoman weeding yang pada umumnya digunakan untuk menetapkan koleksi yang akan disiangi (weeding) adalah:

a. Subject Judgement, yaitu penilaian subjek yang sesuai dengan kebutuhan pemustaka, dapat berdasarkan kurikulum yang berlaku atau berdasarkan mata kuliah maupun jurusan yang ada di perguruan tinggi tersebut.

b. Age, yaitu usia yang dimiliki oleh koleksi perpustakaan. Dalam hal ini berdasarkan tahun terbit buku tersebut.

c. Date of Acquisition, yaitu berdasarkan tanggal pengadaan atau akuisi dari koleksi tersebut dimulai. Hal itu dapat dilihat dari data inventaris koleksi perpustakaan.

d. Use/Circulation, yaitu dapat dilihat dari 
tingkat penggunaan/sirkulasi dari koleksi tersebut. Jadi, dari hal itu dapat dilihat tingkat keterpakaian dan nilai guna dari koleksi tersebut.

e. Shelf Time Period, yaitu berdasarkan periode waktu rak, dapat dilihat dari sisi perputaran di rak. Jadi pemustaka cenderung menggunakan koleksi tersebut, sehingga tidak hanya menetap di rak tersebut atau di tempat yang sama tanpa ada sirkulasi yang terjadi.

Adapun kriteria umum buku yang wajib weeding, menurut Boon (1995) berdasarkan metode CREW (Continuous Review, Evaluation, and Weeding) adalah:

1. Misleading/menyesatkan dari segi kontennya atau isi karena buku tersebut sudah dianggap ketinggalan zaman.

2. Ugly/keadaan buku secara fisik yang sudah usang atau tidak layak pakai, rusak, tidak terpelihara dan tidak dapat diperbaiki lagi.

3. Superseded/buku yang sudah memiliki edisi terbaru maupun edisi revisi dan jumlah duplikatnya terlalu banyak tetapi frekuensi dari pemakaiannya sangat rendah.

4. Trivial/isi atau konten buku kurang bermanfaat karena tidak diperhatikan dan tidak diminati pemustaka.

5. Irrelevant/buku yang tidak sesuai dengan jenis dan tujuan perpustakaan dan juga tidak sesuai dengan kebutuhan pemustaka.

6. AvailableElsewhere/buku yang dapat diperoleh dimana-mana oleh pemustaka tanpa harus ke perpustakaan.

Selain itu, pustakawan harus tetap memperhatikan koleksi yang wajib dilindungi atau dilestarikan walaupun sudah termasuk ke dalam kriteria buku yang wajib disiangi. Adapun kriteria bahan pustaka yang harus dijaga dan tetap disimpan menurut Boon (1995) adalah: a. Koleksi khusus, jika perpustakaan memiliki koleksi khusus di dalam bidang atau subjek tertentu, bahan pustaka yang merupakan bagian dari koleksi jenis tersebut harus tetap disimpan dan dilestarikan.

b. Local content, merupakan koleksi yang bersumber dari lokal (negara atau daerah) karya itu berasal atau koleksi yang bernilai sejarah dan memiliki kandungan informasi lokal yang sangat penting.

c. Nilai sastra, sejarah, atau ilmiah yang luar biasa. Biasanya bahan pustaka seperti ini sudah masuk pada tahapan status klasik ataupun koleksi yang judul-judulnya termasuk ke dalam daftar judul yang direkomendasikan, hal tersebut mencerminkan bahwa para ahli lapangan merasa koleksi tersebut sangat berharga dan memiliki nilai guna yang tinggi, meski telah berusia tua dan secara fisik, buku tersebut sudah sangat rapuh dan sulit untuk diperbaiki kembali.

Keuntungan dari kegiatan penyiangan (weeding) koleksi yang dapat diperoleh oleh perpustakaan adalah:

1. Hemat tempat (save place) karena hanya berisi buku yang mutakhir dan sesuai kebutuhan pemustaka.

2. Hemat waktu (save time), bagi pemustaka akan lebih cepat menemukan bahan pustaka yang dibutuhkan dan bagi pustakawan akan lebih cepat saat shelving.

3. Membuat koleksi lebih menarik (make the collection more appealing) karena hanya terdapat bahan pustaka yang sesuai dengan minat pemustaka.

4. Akan meningkatkan reputasi perpustakaanmu (will enhance your library's reputation) hal tersebut didasari karena perpustakaan akan menjadi tempat utama untuk mencari informasi yang dibutuhkan oleh pemustaka, 
sehingga reputasi perpustakaan pun akan meningkat seiring dengan semakin meningkat pula penilaian pemustaka terhadap perpustakaan tersebut.

5. Memiliki umpan balik yang konstan pada kekuatan dan kelemahan koleksi (have constant feedback on the collection's strength and weakness), yaitu menjadi acuan bagi perpustakaan untuk mengukur kekuatan dan juga kelemahan yang dimiliki dan dapat dinilai kembali untuk dijadikan sebagai peluang bagi perpustakaan.

Sekalipun weeding merupakan bagian penting dari proses pengembangan koleksi, namun masih terdapat perbedaan pendapat terkait dengan kegiatan tersebut yang memicu timbulnya pro dan kontra. Adapun hal yang menyebabkan pro dan kontra tersebut (Rusmana, 2001) adalah:

1. Pandangan pihak yang pro terhadap weeding

a. Koleksi perpustakaan harus tetap disiangi atau diweeding agar jumlah yang telah ditentukan dapat terus dipertahankan.

b. Terdapat keterbatasan pada ruang koleksi. Jadi, harus dimaksimalkan pengguna ruangan tersebut dengan koleksi yang benar-benar dibutuhkan pemustaka.

c. Penyiangan dapat meningkatkan akses pemustaka ke koleksi perpustakaan.

2. Pandangan pihak yang kontra terhadap weeding

a. Pentingnya pelestarian buku, karena merupakan catatan perdaban manusia.

b. Penyiangan merupakan pekerjaan yang dianggap sulit dan merepotkan, jadi harus dilakukan oleh orang yang ahli atau sudah terlatih.

c. Masih banyaknya statement bahwa banyaknya koleksi menunjukkan kehebatan dari perpustakaan tersebut.
Pro dan kontra yang timbul dikalangan pustakawan terhadap kegiatan weeding, pada umumnya didasari oleh paradigma lama yang telah terbentuk di dalam benak pustakawan itu sendiri. Selain itu, hal tersebut juga bisa dipicu oleh kebijakan dari atasan yang cenderung memilih untuk mengumpulkan koleksi perpustakaan dalam jumlah banyak (kontra) ataupun cenderung memperketat seleksi konten yang relevan pada pengguna (pro).

\section{Weeding Koleksi Elektronik}

Perpustakaan perguruan tinggi saat ini sudah meningkatkan pelayanan dalam mengadakan koleksi yang berbentuk elektronik. Jadi, koleksi perpustakaan saat ini tidak hanya terbatas pada koleksi tercetak yang membutuhkan banyak ruang, tetapi juga menyediakan koleksi elektronik seperti e-book, e-journal maupun e-skripsi dll. Kelebihan dari koleksi tersebut yang paling utama adalah dapat diakses dimana saja dan kapan saja tanpa ada batasan ruang dan waktu. Sehingga, keberadaan jenis koleksi tersebut benar-benar mampu mempermudah akses pemustaka terhadap koleksi yang dibutuhkannya.

Namun, hingga saatinisering kaliperpustakaan tersebut tidak memiliki kebijakan weeding terhadap koleksi elektronik. Sebab, kebanyakan dari pustakawan yang ada di perpustakaan tersebut beranggapan bahwa koleksi elektronik tidak memakan banyak tempat. Oleh sebab itulah, koleksi elektronik mendapatkan prioritas terendah dalam kegiatan weeding atau bahkan tidak memiliki prioritas sama sekali.

Alasan perlunya melakukan kegiatan weeding pada koleksi elektronik adalah:

1. Dalam pengadaan e-book, sering kali pustakawan dihadapkan pada pembelian buku yang dalam bentuk paket dan juga mendapatkan versi e-book dari buku tersebut. Maka, terdapat double data pada penginputan 
bahan pustaka tersebut ke dalam sistem informasi yang digunakan oleh perpustakaan.

2. Pemustaka yang melakukan penelusuran informasi, dan memperoleh hasil yang terlalu banyak, dapat memilih buku yang salah, seperti memilih e-book dengan edisi yang lebih tua dari pada buku versi tercetaknya.

3. Subjek-subjek yang memerlukan kemutakhiran atau kebaruan informasi, seperti koleksi eksakta, sangat penting dilakukan weeding pada koleksi elektroniknya. Hal ini dibutuhkan, agar informasi yang disajikan tetap relevan terhadap kebutuhan pemustaka dan tidak menimbulkan kebingungan dalam mencari informasi yang dibutuhkannya.

Adapun tujuan utama dari kegiatan weeding pada koleksi elektronik adalah dapat meningkatkan akses pemustaka terhadap koleksi yang dibutuhkannya dan yang terpenting, tersedianya koleksi termutakhir. Sehingga pemustaka dapat merasakan manfaat dari keberadaan koleksi elektronik tersebut, secara signifikan.

\section{Green Weeding}

Ada beberapa upaya yang dapat dilakukan dalam kegiatan weeding. Hal tersebut sesuai dengan kebijakan yang dilakukan oleh pimpinan suatu perpustakaan. Adakalanya perpustakaan membuat kebijakan weeding dengan menggudangkan koleksi yang weeding, dengan alasan akan menggunakannya sewaktu-waktu jika diperlukan oleh pemustaka kembali.

Selain itu, ada pula yang memilih untuk langsung memusnahkan koleksi yang weeding dengan membakar atau dengan mendigitalkan koleksi tersebut lalu dimusnahkan hard copy-nya. Tentu saja, penyebab utama dilakukan kegiatan weeding adalah kurangnya ruang (space) dan rak bagi koleksi baru yang lebih relevan bagi pemustaka.

Kegiatan weeding dan tindakan serta eksekusi akhir yang dilakukan, tentu saja harus berdasarkan kebijakan weeding yang ada di perpustakaan tersebut. Selain menggudangkan, memusnahkan dan mendigitalisasikan, terdapat satu lagi eksekusi akhir yang dapat menjadi opsi pustakawan, yaitu dengan melakukan Green Weeding.

Menurut Penninman dan McColl dalam Sujana (2011) bahwa green weeding adalah bahan pustaka yang telah dipilih dan ditetapkan untuk dikeluarkan dari daftar koleksi, kemudian diberikan kepada rumah singgah, pusat komunitas, panti wreda, taman bacaan masyarakat, organisasi sosial yang memberikan bantuan buku kepada berbagai pihak yang membutuhkan, menawarkan pada perpustakaan dan pustakawan lain yang lebih membutuhkan.

Berdasarkan defenisi di atas, dapat dimaknai bahwa Green Weeding merupakan salah satu opsi atau pilihan dari kegiatan weeding, yaitu dengan mendistribusikan atau menghibahkan buku-buku yang telah disiangi/weeding berdasarkan kriteria tertentu, agar dapat dimanfaat kembali oleh pihakpihak yang membutuhkan koleksi tersebut.

Adapun manfaat kegiatan Green Weeding adalah:

a. Membangun kerja sama atau kemitraan dengan berbagai perpustakaan, baik perpustakaan yang sejenis dengan perpustakaan pihak penyumbang maupun dengan berbagai taman bacaan yang ada.

b. Dapat memanfaatkan kembali buku yang telah dianggap usang atau useless oleh perpustakaan tertentu, namun masih memiliki nilai guna yang tinggi pada perpustakaan yang lainnya.

c. Menjadi alternatif atau opsi tambahan bagi perpustakaan yang melakukan kegiatan weeding secara rutin dan berkala.

d. Terawat dan terpeliharanya buku-buku yang didistribusikan ataupun dihibahkan tersebut, karena benar-benar dimanfaatkan oleh pihak yang menerima dan tersalurkannya 
buku-buku tersebut kepada pihak-pihak yang lebih membutuhkan.

Menurut Bestari (2016), alur kegiatan green weeding yang pada umumnya sering digunakan adalah:

1. Pembentukan tim penyiangan koleksi

2. Menyusun jadwal kegiatan penyiangan koleksi

3. Melakukan pendataan koleksi out of date

4. Pengambilan koleksi out of date pada rak

5. Pemindahan koleksi pada rak out of date dan pendataan koleksi di atas 20 tahun

6. Penyusunan daftar koleksi buku out of date untuk dihibahkan

7. Pengajuan permohonan koleksi out of date untuk dihibahkan

8. Penyebaran informasi hibah buku kepada pihak internal dan eksternal perpustakaan

9. Pendaftaran peminat hibar buku

10. Pengemasan buku yang diminati oleh peminat hibah buku

11. Melakukan penyerahan hibah buku kepada peminat dengan penandatanganan berita acara

\section{METODOLOGI}

Adapun metodologi penelitian yang digunakan penulis adalah metode deskriptif kualitatif. Penelitian deskriptif biasanya disebut juga penelitian taksonomik, yang dimaksudkan untuk eksplorasi dan klarifikasi mengenai suatu fenomena atau kenyataan sosial dengan jalan mendeskripsikan sejumlah variabel yang diteliti. Sedangkan kualitatif merupakan penelitian yang dimaksudkan untuk memahami fenomena tentang apa yang dialami oleh subjek secara holistik dan dengan pendeskripsian dalam bentuk kata-kata (Lubis, h. 2). Metode deskriptif kualitatif ini sangat cocok dalam penelitian ini karena penulis dalam hal ini berusaha untuk menggambarkan dampak implementasi Green Weeding terhadap pemanfaatan koleksi usang pada perpustakaan perguruan tinggi.
Sehingga, fenomena tersebut dapat terungkap secara jelas dan akurat.

Adapun instrumen penelitian yang digunakan adalah interview. Dalam hal ini, wawancara digunakan untuk memperoleh informasi secara verbal dari responden. Jadi, tujuan wawancara ini adalah untuk memperoleh informasi tentang kegiatan weeding yang telah dilakukan di Perpustakaan UII.

\section{PEMBAHASAN}

\section{Kasus di Perpustakaan UII}

Perpustakaan Universitas Islam Indonesia (UII), Yogyakarta melakukan kegiatan weeding sekali dalam setahun. Hal tersebut dilakukan berdasarkan kebijakan yang berlaku di perpustakaan tersebut. Kriteria buku yang disiangi/weeding di perpustakaan tersebut adalah buku yang sudah lama dan tidak dimanfaatkan lagi oleh pemustaka, serta buku yang sudah memiliki edisi revisi. Selain itu, koleksi yang tersentuh oleh kebijakan weeding di perpustakaan tersebut adalah koleksi buku dan majalah usang yang sudah memenuhi kriteria weeding. Sedangkan untuk koleksi e-book, e-journal, e-TA, e-skripsi maupun koleksi CD tidak diweedingkan karena memang belum ada kebijakan dari perpustakaan terkait weeding untuk koleksi tersebut.

Kegiatan weeding diperpustakaanUll dilakukan dengan dua cara, yaitu dengan mendigitalkan dan menggudangkan koleksi tersebut. Buku yang telah digudangkan memiliki tujuan yaitu, jika sewaktuwaktu dibutuhkan lagi, maka akan dapat langsung diakses ke gudang dan diaktifkan kembali di SIMPUS (Sistem Informasi Manajemen Perpustakaan). Sedangkan untuk koleksi majalah yang disiangi/ weeding, terlebih dahulu didigitalkan dan diinput ke dalam e-Librarian, setelah itu baru dimusnahkan dengan dibakar.

Untuk sistem penelusuran informasinya, OPAC (Online Public Access Catalague) digunakan hanya untuk hard copy saja yaitu buku dan penelusuran 
sistem informasinya tidak digabungkan dengan yang e-book, e-journal, e-TA maupun e-skripsi karena dapat diakses di e-Librarian. Sehingga, tidak ada ketimpangan dalam hasil penelurusan yang dilakukan oleh pemustaka terhadap koleksi yang bersifat hard copy dan yang berbentuk elektronik. Sedangkan untuk buku yang rusak, langsung dipreservasi dengan diserahkan langsung ke pihak pelayanan teknis dan sejauh ini, tidak pernah langsung masuk ke tahap weeding karena buku tersebut masih memiliki nilai guna atau tingkat pemanfaatan yang tinggi.

Pada perpustakaan UII tidak ada kegiatan Green Weeding yang dalam hal ini diartikan sebagai kegiatan penyumbangan buku kepada lembaga atau taman bacaan tertentu. Hal utama yang mendasarinya adalah adanya kemungkinan pemustaka membutuhkan buku yang telah disiangi (weeding), maka dapat langsung diakses ke gudang dan langsung diaktifkan di SIMPUS UII.

\section{Diskusi}

Perpustakaan Universitas Islam Indonesia (UII), secara rutin pertahunnya telah melaksanakan kegiatan weeding berdasarkan kebijakan yang dimiliki oleh perpustakaan tersebut. Bahkan bahan pustaka atau buku yang disiangi/weeding, selalu dalam jumlah yang cukup besar, baik dari segi judul maupun eksemplarnya.

Data weeding di perpustakaan UII yang diperoleh penulis sebagai sampel diskusi pada artikel ini adalah sejak tahun 2016 hingga tahun 2018. Berdasarkan lampiran kegiatan weeding Perpustakaan UII, adapun jumlah judul dan total eksemplarnya adalah:

Tabel 1 Jumlah buku yang disiangi/weeding

\begin{tabular}{|c|c|c|}
\hline Tahun & Jumlah Judul & Jumlah Eksemplar \\
\hline 2016 & 468 & 987 \\
\hline 2017 & 836 & 1934 \\
\hline 2018 & 409 & 648 \\
\hline Jumlah & $\mathbf{1 7 1 3}$ & $\mathbf{3 5 6 9}$ \\
\hline
\end{tabular}

Sumber: Perpustakaan Universitas Islam Indonesia (UII) Yogyakarta.
Dari data lampiran kegiatan weeding di perpustakaan UII sejak tahun 2016 hingga tahun 2018 berdasarkan tabel 1, bahwa buku yang telah disiangi/weeding berjumlah 1713 judul dengan total 3569 eksemplar. Berdasarkan keterangan Bapak Ismanto, A.Md selaku Kadiv Pelayanan di Perpustakaan UII, bahwa keseluruhan dari buku yang disiangi/weeding tersebut telah digudangkan.

Buku-buku yang disiangi/weeding tersebut digudangkan dan tidak ada kegiatan perawatan terhadap sejumlah besar buku yang terdapat di dalam gudang tersebut. Padahal, buku yang di dalam gudang, berpotensi rusak karena faktor cahaya, kelembaban dan debu. Apalagi buku-buku tersebut telah berada di dalam gudang dalam waktu yang relatif lama.

Berdasarkan informasi yang diperoleh penulis melalui sesi wawancara dengan BapakIsmanto, A.Md bahwa Perpustakaan UII tidak melakukan kegiatan green weeding dalam hal ini dimaknai sebagai pendisitribusian atau menyumbangkan buku yang disiangi/weeding kepada lembaga maupun perpustakaan tertentu guna memanfaatkan kembali koleksi yang dianggap usang (useless) oleh perpustakaan tersebut karena sudah tidak sesuai lagi dengan kebutuhan pemustakanya.

Kiranya, dapat dinyatakan bahwa koleksi yang berjumlah lebih dari tiga ribu eksemplar tersebut digudangkan dan tanpa perawatan, yang kemungkinan besar akan cepat rusak seiring waktu yang disebabkan oleh beragam faktor yang memicu kerusakan buku. Buku-buku tersebut hanya dapat keluar dari gudang dan dimanfaat kembali jika diperlukan oleh pemustaka, kemudian pihak perpustakaan akan langsung mengakses ke gudang dan mengaktifkan buku tersebut ke SIMPUS UII.

\section{E. SIMPULAN}

Adapun simpulan yang diperoleh adalah:

1. Weeding merupakan kegiatan perpustakaan yang menyeleksi dan menarik bahan pustaka 
dari rak atau area koleksi utama berdasarkan kriteria yang telah ditentukan, guna memberikan space baru bagi koleksi yang diadakan kembali sesuai dengan kebutuhan pemustaka.

2. Kegiatan weeding masih memiliki beragam pandangan dan alasan yang pro dan kontra di kalangan pustakawan dalam pelaksanaannya.

3. Green weeding merupakan salah satu opsi atau alternatif dari kegiatan weeding, yaitu dengan mendistribusikan buku-buku yang telah disiangi (weeding) berdasarkan kriteria yang sesuai dengan kebijakan, agar dapat dimanfaat kembali oleh pihak-pihak yang membutuhkan koleksi tersebut.

4. Green weeding memiliki manfaat dalam menjalin kerja sama atau kemitraan dengan perpustakaan dan taman bacaan lainnya.

5. Perpustakaan UII merupakan perpustakaan yang rutin melaksanakan kegiatan weeding yaitu sekali dalam setahun berdasarkan kebijakan dari perpustakaan tersebut, guna memutakhirkan koleksi yang dimiliki.

6. Bahan pustaka yang disiangi/weeding di Perpustakaan UII adalah koleksi buku dan majalah usang.

7. Perpustakaan UII tidak melakukan kegiatan green weeding dengan alasan sewaktu-waktu buku yang digudangkan diperlukan kembali, dapat langsung diakses dan diaktifkan kembali ke SIMPUS UII.

Adapun saran yang dapat penulis berikan kepada Perpustakaan UII adalah:

1. Untuk melakukan kegiatan green weeding guna lebih memanfaatkan kembali dan menaikkan nilai guna dari koleksi perpustakaan yang telah disiangi (weeding).

2. Menjalin kerja sama atau bermitra dengan berbagai perpustakaan ataupun lembaga maupun taman bacaan melalui kegiatan green weeding.
3. Jika Perpustakaan UII tidak melakukan kegiatan green weeding karena berbagai faktor dan alasan, hendaknya buku-buku yang digudangkan tetap mendapatkan perawatan dan perhatian, karena jika sewaktu-waktu ada pemustaka yang membutuhkan buku yang telah digudangkan, pemustaka tersebut dapat memperoleh buku yang dibutuhkannya dalam keadaan baik dan layak pakai secara fisik.

\section{DAFTAR PUSTAKA}

Bestari, M. P. (2016). Implementasi Penyiangan Sebagai Evaluasi Memutakhirkan Koleksi Perpustakaan dalam Mendukung Kualitas Pengajaran di STIE Perbanas Surabaya. Pustaka. $8(2)$.

Boon, B. (1995). Expanded Guidelines For Collection Evaluation And Weeding For Small And Medium Sized Public Libraries. Diakses pada 10 November 2018, dari Lili.Org/Forlibs/Ce/Able/ Course4/05criteria.Htm.

Lubis, E. Penelitian Deskriptif (Kualitatif). (n.d). Diakses dari http://www.academia. edu/30373783/penelitian_deskriptif_ kualitatif.

Reitz, J. M. (2004). Dictionary for library and information science. Connecticut: Libraries Unlimited.

Rusmana, A., Ninis, A. D., \&Winoto Y. (2001). Beberapa Faktor Yang Mempengaruhi Para Pengelola Perpustakaan Terhadap Pelaksanaan Kegiatan Penyiangan (Weeding) Bahan Pustaka. Jurnal sosiohumaniora, 3(3), 199-216.

Sujana, Janti G. (2011). Weeding: Membuat Akses Pada Koleksi Lebih Baik. Jurnal Pustakawan Indonesia, 11(1), 15-19.

Urwanto, E.(2017).Penyiangan Koleksi Perpustakaan: Studi Kasus Di Perpustakaan Bung Karno Blitar pada Lokakarya Pustakawan di Lingkungan Perpustakaan Nasional RI, (powerpoint), 14 Desember 2017. 